\title{
OPULENCIA E MISERIA
}

Sempre que se fala em crise, em pobreza, logo acóde $o$ interlocutor, dizendo que, na vespera, esteve num hotel luxuoso, num palacete, numa festa de gente millionaria, e que se admirou, ao contrario, da riqueza, da opulencia, do luxo de que foi testemunha. Mas é sabido, sabidissimo, que muito commum é, numa mesma sociedade, acotovelarem-se a riqueza e a miseria. Logo no começo de sua "Economia Politica", refere Stuart Mill que a crença geral da riqueza da India provém de haver naquelle paiz certas ordens religiosas, certos institutos opulentos que apparentam um luxo verdadeiramente oriental. A quasi totalidade da população porém, diz elle, geme sob a maior pobreza. Schmoller, Wagner e outros dão sua melhor attenção aos indicios com que se possa reconhecer si ha bem estar na maioria da população de um paiz.

Concretizarei. E' meu exemplo a Inglaterra; paiz cuja riqueza tantos outros invejam: basta, diz-se, em geral, que o operario, com a picareta, abra a boa terra, para encontrar o carvão, o pão negro da industria, o que vale dizer "ouro" Mas a Inglaterra é a terra proverbial da mais negra miseria. Aconselha o grande economista Gide a leitura das obras de Booth e de Rowntry para se formar uma idéa do pauperrismo inglez. A miseria em Londres excede tudo quanto poderia uma imaginação dantesca crear. Dikens, em muitas de suas impressionadoras obras, Ramalho Ortigão, em "John Bull", e innumeros outros escriptores, dignos de credito, nol-o attestam. Por milhares, tremem de frio ao relento os cidadãos inglezes du- 
rante as noites gelidas daquella terrivel cidade dos nevoeiros; aquecem alguns infelizes as mãos nas flammas das luzes accesas nos logares onde ha, nas ruas el caminhos, perigo para os transeuntes, dormem outros sobre os bancos dos jardins, quando não são despertados e expulsos pelos guardas policiaes e do mesmo modo que esses miseraveis, ha milhares de individuos que passam a vida sem tecto, sem meios de se alimentar, a não serem os que lhes depara a sorte do dia. Esfaimados, vagam pelas ruas da "opulenta" metropole. Ha cerca de meio seculo, quanido começou a accentuar-se o movimento popular contra a defeituosa organização economica do Reino, houve procissões pelas ruas de Londres, nas quaes era levado um pão feito na Inglaterra, e outro vindo da Polonia, sendo ambos do mesmo preço, mas de tamanhos muito differentes: pequeno o inglez, e grande o polaco. Queria com isto dizer o povo que a producção do carvão e o serviço das industrias manufactureiras obrigavam a Inglaterra a não produzir alimentos, donde a necessidade de os adquirir fóra, de os comprar em paizes em que as forças productoras se destinam á util producção de alimentos, es de tudo quanto precisa a massa da população, ficando ainda o povo em condiçōes de exportar sobras. Nos Estados Unidos, disse, ha dias, uma folha desta capital, a população dos districtos em que havia a monocultura do algodão teve a idéa de erguer um monumento á lagarta rosada, porque esta anniquilava a producção tdo artigo que o povo julgava causa da miseria da maioria, e da opulencia de uma pequena classe. Teria razão o povo? Eis o que não posso elucidar neste fugidio artigo, nem mesmo isto me interessa no momento: o que quero fazer vêr é unicamente que ha muitos logares em que, ao lado de uma pequena classe de millionarios, ha uma outra muito maior de pobres, e mesmo de miseraveis, ameaçando gerar o pauperrismo (no sentido technico do vocabulo), uma das maiores calamidades sociaes. 
São estas as condições de São Paulo? E' possivel que não sejam tão accentuadas quanto as dà Inglaterra ou as da India, mas a má distribuição da riqueza é innegavel. Ha uma bem elevada classe de indigentes em nossa capita!, e só mesmo a cegueira da riqueza póde: impedir que seja o mal visto por todos os bafejados da fortuna.

Faz cerca de um mez, por volta de 9 horas da noite, eu me dirigia para o centro da cidade, em companhia de um hospede do Hotel Regina e de um outro do Esplanada. Passavamos pelo Viaducto de Santa Ephigentia, quando notei certa pobre mulher acocorada e envolta em uma coberta que lhe occultava todo o corpo. Como fossem meus companheiros de fóra de São Paulo, disse-lhes eu que assim passaria a mulher a noite ao relento; que o valle do Anhangabahú é o ponto mais frequentado pelos noctambulos, destituidos (para seu mal) do fogo sagrado que aquecia os antigos aventureiros e bandeirantes "senza cuna e senza letto" Admiraram-e os hospedes, e é provavel que tenham lido, depois, nos nossos jornaes, haver muitos desgraçados que luciam o dia todo com o escopo de terem um modesto quarto a $3 \$ 000$ no bairro da Luz, segundo informações de "reporters" dignos de fé. Noticía, além disso, nossa imprensa ser elevadissimo o numero dos infelizes que dormem sobre os bancos de pedra dos jardins publicos. nos vestibulos abertos de monumentos, sob os viaductos, sob as pontes e até nas privadas, onde buscam abrigo contra as imtemperies durante as noites tempestuosas.

Já pensou o leitor na sorte desses desgraçados? Provavelmente porém lembra-se do Rei Lear e de seu delirio durante a noite em que ficou exposto ao léo: "Arranca os cabellos brancos que o tufão impetuoso com raiva céga dispersa pelos ares, como se the servissem de ludibrio; oppõe todas as forças de seu organismo, com desespero, ao enorme sibilar do vento, ao zunir da chuva! Nesta noite não sáe a ùrsa que aleita os filhos do covil, nem o lobo, 
nem o leão esfaimado, mas elle lá anda, com a cabeça descoberta a bramir contra tudo e contra todos"

Quem sabe si não se recorda o leitor do ponto em que o Rei Lear sente remordel-o a consciencia, porque não cuidou de seus subditos noctambulos, desgraçados cujos tormientos elle então experimentava? Diz elle: "Pobres dos miseraveis nús: onde quer que estejaes, recebeis o furor desta impiedosa tempestade. Como é que vós com as vossas cabeças sem abrigo e sem tecto, os vossos ventres sem alimento, mal cobertos de deploraveis farrapos todos esburacados, podereis defender-vos idum tempo como este? Ai! "Quantas vezes esqueci vossas desgraças"? Oh! luxo devorador. Experimenta o remedio: "expõe-te a soffrer o que os miseraveis soffrem"; espalha por elles o superfluo; mostra-lhes a justiça dos céos" (Trad. de D. Ramos). Assim é: não conhecem os felizes o que é a vida dos desgraçados. Além da lucta de classes, ha a separação, que véla saibam umás as necessidades das outras

Não ha muito, referia eu, em uma roda de burguezes abastados, que os meninos vendedores de: jornaes durante o dia e nas primeiras horas da noite, procuram, cerca de dez horas da noite, as salas ou os corredores das redacçóes dos jornaes, onde, deitados, tendo por cama o paletot, ou mesmo sobre o soalho nú, conseguem algumas horas de repouso para recomeçarem a faina na madrugada immediata. Um dos bons homens que me ouviam perguntoume si tal faziam por "peraltice, para não irem para a casa paterna" Revidei, que, morando em bairros afastados, força lhes era, pela falta de transportes, passarem a noite em tão má situação, quando a Paulicéa dorme reclinada sobre o Tamanduatehy.

$E$ ' isto: as classes abastadas ignoram o que seja a vida do pobre. Excepcionalmente o medico, alguns advogados e os sacerdotes conhecem a miseria popular. 
Em um de seus bellissimos estudos sobre a vida rural na Inglaterra, affirma Washington Irving que a caça tem, naquelle paiz, a vantagem de approximar amos e trabalhadores ruraes, estabelecendo certas trocas de idéas entre as duas classes. Tambem ao tempo da grande guerra, diziam os jornaes francezes que a communhão de vida nas trincheiras, approximando, em consequencia do serviço militar obrigatorio, todas as classes, teria como salutar consequencia ficarem conhecendo as classes abastadas a vida do pobre. Não creio no valor de taes factores de melhoramento nas relações entre as classes. Para mim, nenhum melhor factor de approximação haverá do queı a imprensa "livre, mas livre mesmo, livre de verdade". Emquanto as classes não puderem falar livremente, emquanto houver peias á manifestação do pensamento, não poderá uma classe saber o que pensa della a outra. Ailgumas dezenas de soldados nas trincheiras, alguns nobres caçadores com seus empregądos não pódem saber o que é o soffrimento de todas as horas dos que na sociedade se designam pela phrase: "Nos numerus sumus"

Ha todavia janellas por onde podem os ricos lobrigar scenas de miseria, de extrema pobreza. Nas instituições de caridade, "nas obras", como hoje se diz, para significar as corporações animadas por benemeritos philanthropos (nunca assás louvados), é facil formar um juizo do que seja a indigencia de elevado numero de nossos concidadãos. Ao visitar, em Junho de 1924, a Santa Casa de Misericordia (instituição para cujo louvor não ha palavras em nossa lingua), disse o actual Presidente ido Estado que reconhecia a carencia de recursos com que lutava aquella excellente instituição de caridade. Era, com effeito, não obstante tołlo o esforço das benemeritas e caridosissimas pessôas que lhe dedicam toda a sua attenção, e que fazem por ella os maiores sacrificios, um estabelecimento que, só por falta de dinheiro, muito deixava, e deixa a desejar. 
Um illustre literato paulista pintou o que viu lá como sendo uma miniatura do Inferno de Dante. Fez, entretanto, repito, um punhado de abnegados pelo hospital tudo quanto é dado aos individuos: só resta a acção do Estado ser mais efficaz. $O$ que se diz da Misericordia paulista póde ser affirmado das outras instituições que a iniciativa individual creou em nossa capital. Tem-se feito muito, quanto é possivel ao individuo: é a vez do Estado.

A este cumpre organizar o trabalho, procurar que o individuo dê seus esforços á sociedade de que faz parte, que seja reduzido ao minimo o numero de ociosos, mas : ha um momento em que força é reconhecer que toda a deligencia por parte dos individuos e do Estado é impossivel para evitar a miseria, e então apparece a acção dos soccorros publicos com que estou a occupar-me. Em sum- ma: evitar a pobreza, usar dos remedios necessarios, dar as providencias aconselhadas pela Economia Politica para reduzir ao minimo o numero de pobres na communhão social, mas soccorrer aquelles que, em consequencia de uma fatalidade inevitavel ou pela má organização de nossa sociedade, se tornaram um encargo para o corpo social.

Fiz o diagnostico ou melhor a anamnese. Em outro artigo occupar-me-ei com a therapeutica, com os remedios, com os medicamentos que me parecem mais proveitosos. 